\title{
Jordi Salat: a truly interdisciplinary oceanographer
}

\author{
Mikhail Emelianov, Antonio Cruzado, María Pilar Olivar, Jordi Lleonart
}

Institut de Ciències del Mar-CSIC, Pg. Marítim de la Barceloneta 37-49, 08003 Barcelona, Catalunya, Spain.

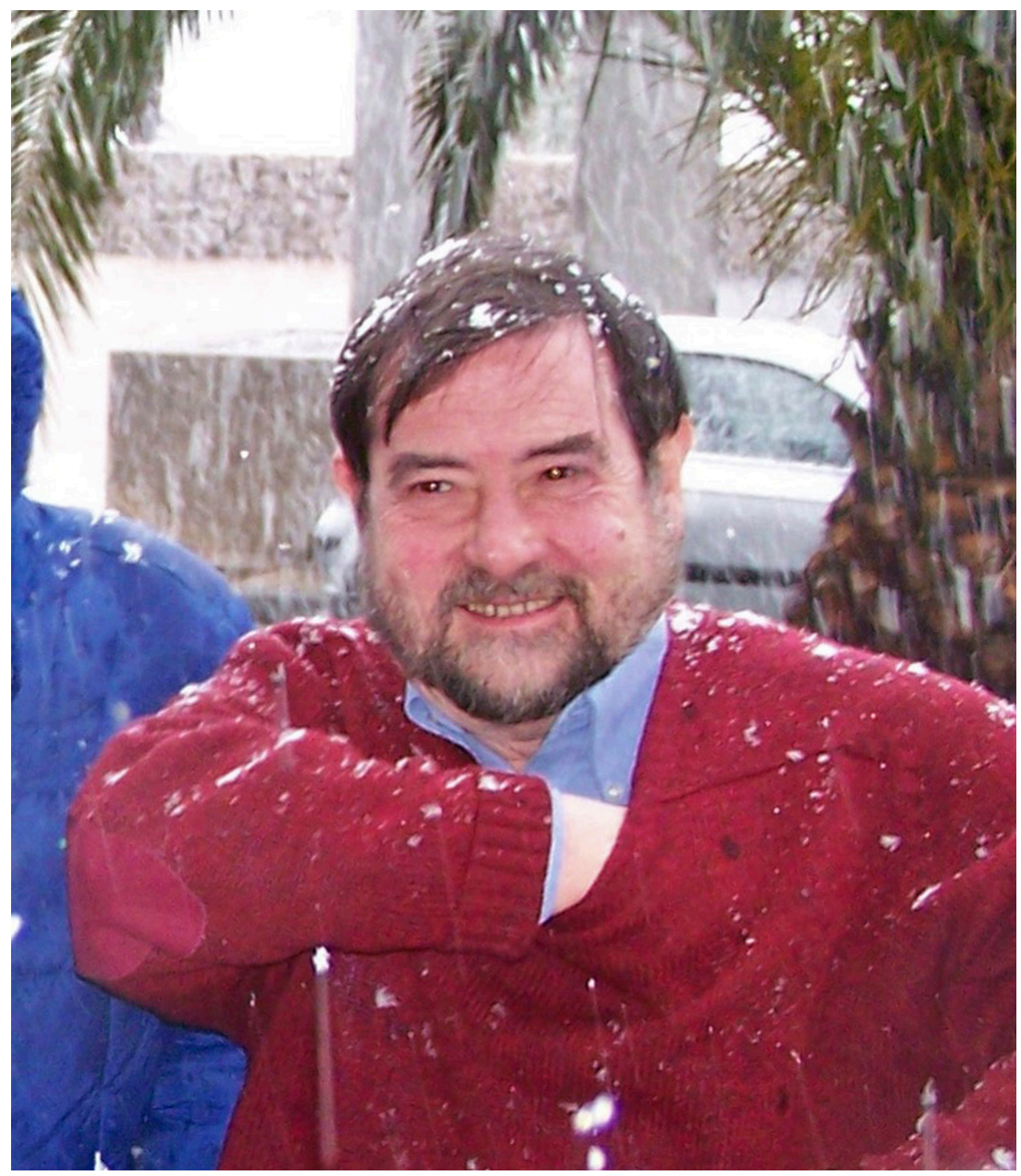

When you talk about oceanography with Jordi Salat, no matter which of the world's currents or water masses you refer to, he will be able to tell you something peculiar about it. And his physical insight will often come with a complementary explanation on its biological properties or the fisheries you can find there. $\mathrm{He}$ is indeed full of surprises and possibly the best example of a truly interdisciplinary oceanographer: a mathematician and specialist in water masses who has used his skills to reveal the physical and biological responses that occur in many of the world's oceans. $\mathrm{He}$ is also the best expert in the water masses of the Mediterranean Sea at the Institute of Marine Sciences (Institut de Ciències del Mar, ICM).

This article describes the career and some of the scientific accomplishments of Jordi Salat from the viewpoint of his colleagues at the Physical Oceanography and Living Resources departments of the ICM. 
The first section ("Salat's early oceanography years") is a remembrance by Antonio Cruzado on Salat's early years as an oceanographer, from the time when the two worked together at the ICM (formerly the Instituto de Investigaciones Pesqueras, IIP). In the following section ("Contributions of Jordi Salat to fisheries oceanography”), Pilar Olivar and Jordi Lleonart gather some of their memories on how Salat has always played a key role in interpreting the distribution of fishery species in the Mediterranean and off the West African coast. Finally, in the last section ("The western Mediterranean oceanographer"), Mikhail Emelianov picks up on Salat's work during the last two decades, which has established him as an internationally recognized expert on western Mediterranean oceanography.

This text is, above all, a reflection on how Salat has shared his experience and ideas over the years, influencing the work of many people. It is a small token of gratitude to an excellent scientist, who is at once passionate and emotional, a good person and a wonderful friend. Salat has successfully combined his interdisciplinary oceanographic research with teaching activities at the Universitat Pompeu Fabra in Barcelona. He has participated in over 40 oceanographic cruises, often as the chief scientist, and has been and is a member of several expert committees. He has published over 150 papers, book chapters and technical/data reports, about half of which are articles in Science Citation Journals.

\section{Salat's early oceanography years}

Jordi Salat first arrived at the ICM around 1967, when he was a young mathematics student at the University of Barcelona. He was given a grant by the $\mathrm{Pa}$ tronato Juan de la Cierva, the mother institution of the IIP, and started working under the supervision of Antoni Ballester. In 1969, Ballester organized a cruise on board the Belgian Navy ship N/O Mechelen going from Oostende to Barcelona with Jordi Salat, Agustí Julià and myself as scientific crew, under the sponsorship of the Institut Royal des Sciences Naturelles de Belgique and the North Atlantic Treaty Organization. We towed a vehicle with a hose and a pump, hence providing a continuous flow of sea water to an AutoAnalyzer, which had recently been introduced in oceanography. The method was a very sound way of using the mapping of the near-surface nitrate concentration to track features such as the upwelling frontal system off the coast of Portugal and the surface contrasts created by the opposing flows at Gibraltar and in the Alboran Sea.

In 1970, an IBM 1130 computing system on loan from IBM, which was enormous despite its low memory capacity, was installed in one wing of the Aquarium of the old IIP building (it was eventually moved to the central lobby). Jordi was one of the scientists who took most advantage of this computer (Fig. 1). A similar machine, installed on board the Spanish R/V Cornide de Saavedra in the early 1970s, was also used by Jordi on some of its initial cruises.

In 1970, Antoni Ballester organized a UNESCO Course on Marine Chemistry and Jordi's involvement was fundamental for carrying out this course.

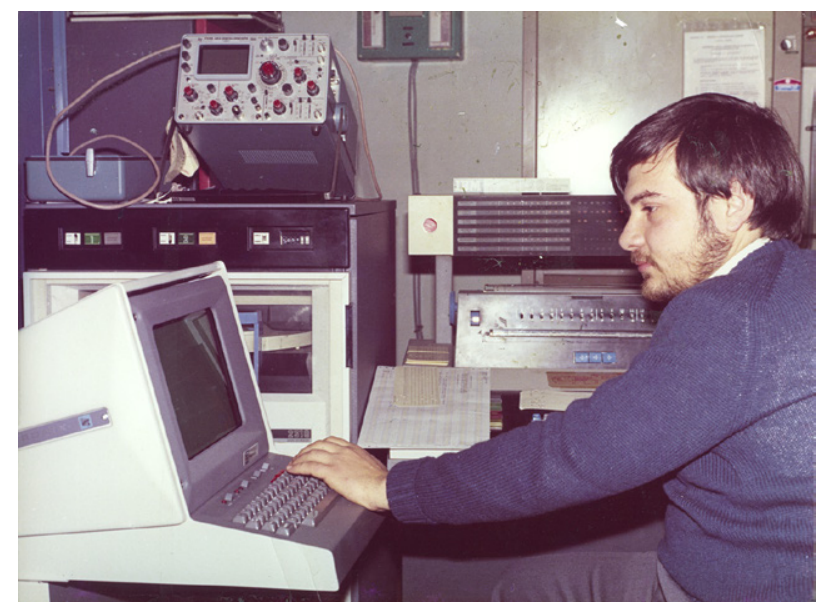

Fig. 1. - Jordi Salat working with the IBM 1130 computing system in the early 1970s. Source: Emilio Garcia Ladona.

During the 1970s, a small-scale study of the Gulf of Sant Jordi, located on the northern side of the River Ebro Delta, was carried out using a fishing boat; Jordi participated in these cruises, together with visitors from Chile and Cuba and myself (Salat et al. 1978). That same year, a survey of the extent of oil pollution produced from the Polycommander wreckage in the Ria de Vigo, NW Spain, was also done with the same participants.

The continuous-analysis strategy, which won a price from the Patronato Juan de la Cierva (Ballester et al. 1972), was further extended to other nutrients such as silicate and phosphate. This sampling and analysis strategy was used on several cruises carried out off the Western Sahara on board the R/V Cornide de Saavedra between 1971 and 1975, while studying the coastal upwelling conditions in the area between the Canary Islands and Cape Vert (Cruzado and Salat 1981).

In 1973 Jordi completed his degree in Mathematics and was given a job at the IIP, where he has remained until today. In 1975, I went to serve for a year at the Intergovernmental Oceanographic Commission of UNESCO; one outcome of this was our contribution to the DRIFTEX experiment, studying the current system in the NW Mediterranean Sea. Thousands of floating cards were thrown into the sea from liner ships between Genova and Corsica, and some 550 cards were recovered at various locations of the coastline, mainly off France and Spain. From the recorded retrieved locations, Jordi and myself were able to model the current system in the NW Mediterranean Sea. This was probably the start of Jordi's extensive career working on the hydrography of the Mediterranean Sea, which involved numerous collaborations with experts of the region, gathered around the meetings of the Commission Internationale pour l'Exploration Scientifique de la Méditerranée (CIESM).

In 1979, when the R/V García del Cid came into service, opening a completely new area of research in the Catalan Sea, Jordi actually participated in the inaugural cruise. In 1980 we were awarded an important project to study the Catalan Sea by the Spanish Scientific Research Commission (Comisión Interministerial 
de Ciencia y Tecnología, CICYT), possibly the first one they had ever awarded. We acquired a conductivity-temperature-depth (CTD) device and a computerized data acquisition system, and this was placed in operation on board the R/V García del Cid with Jordi's support.

In 1981, as I went to serve the United Nations Environment Programme action plan for the Mediterranean Sea, Jordi took the leadership of the project and organized several cruises that provided some of the early detailed descriptions of the distribution and variability of water masses of the Mediterranean Sea (Estrada et al. 1999, Salat et al. 2002, Arin et al. 2005). In 1984 I moved to Blanes, to help set up a new marine institute, and my collaborations with Jordi became less frequent.

\section{Contributions of Jordi Salat to fisheries oceanography}

Jordi Salat's skills extend beyond pure physical oceanography and also embrace the interpretation of biological patterns through the combined analysis of the distribution of organisms and the underlining hydrography. He has been the most constant collaborator of numerous biologists at the ICM-CSIC and, for many of those who began our doctoral work in the 1980s, he was the unofficial teacher in biological oceanography. His old blackboard, where he has written down schemes, graphs and formulae, has followed him to the various offices to which he has been forced to move over the years. He enjoys field work and careful data analysis, which give him the necessary insight into the physical phenomena and a wide scope for the biological importance of these processes. Working with Jordi on the interpretation of data is a singular experience, in which he poses possible connections that often lead to unexpected explanations.

Starting back in the 1980s, Jordi pioneered many studies on primary production and phytoplankton distribution patterns of mesoscale structures in the Mediterranean Sea in collaboration with Marta Estrada (Estrada and Salat 1999). However, his greatest interdisciplinary contribution was possibly establishing the relations between ichthyoplankton patterns and their environmental scenarios. The collaborations started in 1979 when he was studying the Benguela Current, within a project aimed at studying the fisheries off Namibia, but were later extended to studies conducted in the Mediterranean Sea, Benguela and Canary upwelling regions, and even to the Indian and Pacific Oceans.

In the early Namibian surveys, Jordi was the only oceanographer on board, taking care of a great variety of aspects, such as the setting of the Niskin bottles, the reading of the thermometers and the calibration of salinity, plus helping with the gear operations for plankton sampling. As a result, he was the co-author of six papers dealing with the ichthyoplankton and hydrography of the southern African coasts, showing the important effect of the offshore Ekman transport on the horizontal patterns of fish larval distributions (Olivar et al. 1992).
Jordi was also responsible for the oceanographic tasks of an Areces project in the early 1980s, and in subsequent projects aimed at establishing patterns of distribution of ichthyoplankton and fish recruitment in the Mediterranean Sea. As a result, he contributed to 11 scientific articles, which included extensive reviews on the interactions between the marine environment and the distributions of ichthyoplankton and small pelagic fish (Palomera et al. 2007, Sabatés et al. 2007).

More recently, Jordi has become interested in how climate change affects the early stages of fishes in the NW Mediterranean, and he has collaborated in a transoceanic study across the Atlantic, Indian and Pacific Oceans to ascertain the influence of environmental variables on the distribution patterns of migratory fish.

Jordi also made some forays into the world of fisheries, mainly as a mathematician (Fig. 2). When asked for help he went to the aid of his fellow biologists, helping with multivariate statistics and population dynamics modelling. The collaboration started in the framework of the Namibian project, as he worked on the development of dynamic production models and on virtual population analysis (VPA) of hake, which included cannibalism, as well as on multispecies VPA (Lleonart et al. 1985). This association has remained uninterrupted over time, leading to over 15 papers on stock assessment and population dynamics.

Jordi early developed software for stock assessment in a data-poor context, and it is still under use for studying many cases of Mediterranean fisheries (Lleonart and Salat 1992). In the topic of fisheries modelling, he collaborated in the analysis of gear competition and in the development of a bio-economic model (Lleonart et al. 1996, 2013). He also worked on the compensation of allometric growth in multivariate morphometric analysis (Lleonart et al. 2000), a methodology that has been extensively used.

As fishery biologists, we have learnt to appreciate Jordi's skill in appreciating the connections between the physical environment and the distribution of ichthyoplankton, as well as his analytical mind in modelling population dynamics, unravelling many aspects that would have otherwise remained unclear.

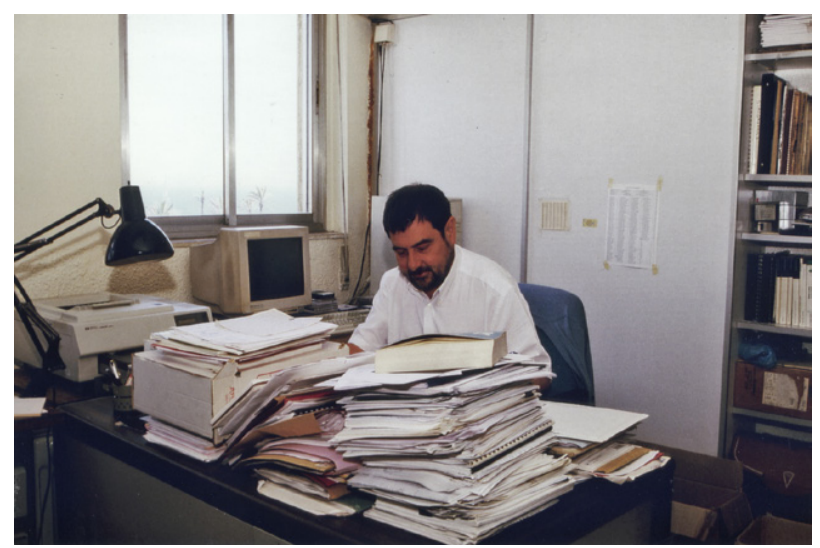

Fig. 2. - Jordi Salat at work in his office in the old IIP building. Source: Emilio Garcia Ladona. 

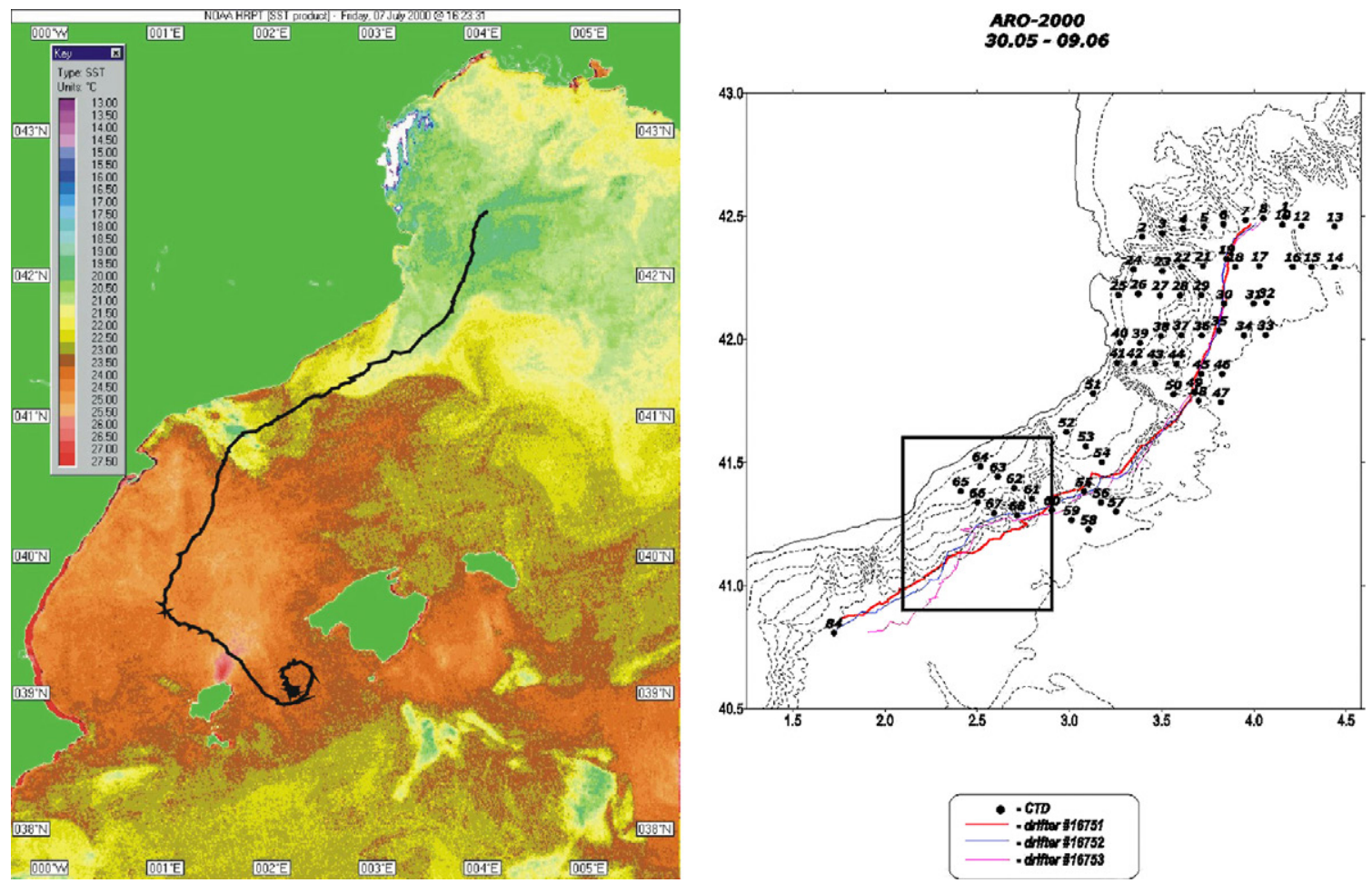

Fig. 3. - Trajectory of a drifter superimposed on top of the sea-surface-temperature field as deduced through satellite IR imagery. The inset illustrates the trajectories of three drifters during the oceanographic survey mentioned in the text. Source: Mikhail Emelianov.

\section{The western Mediterranean oceanographer}

I met Jordi Salat in February 1996, shortly after I arrived in Barcelona to work at the ICM. My first impression was that, though he was somewhat reserved, Jordi was always ready to lend a helping hand. And this perception was reaffirmed when I had the opportunity to work with him on a cruise. Seamen know that onboard a vessel we retain our terrestrial mask usually no longer than a couple of days: the sea rips off the mask and reveals the true nature of a person. I have rarely seen an oceanographer who is so immersed-I would say in love-with the sea as Jordi.

On one of the Mediterranean expeditions on board the R/V García del Cid, we had been studying the transport of anchovy larvae by the Catalan Current, which starts in the Gulf of Lions and follows along the border of the continental shelf. We had planned to trace the current with satellite-tracked Lagrangian drifters, so that we could follow them and carry out CTD casts. How could we determine the place to launch the drifters, being in the open sea without satellite images on board? As our vessel was slowly drifting in the central part of the Gulf of Lions, Jordi glanced at the records of the surface thermosalinograph (which he had introduced as a standard for all ICM's oceanographic cruises) and came on deck looking away and thinking... Suddenly he said: "Quick! Prepare the drifters for launching! Let's start here." And so we did, and all three drifters proceeded along the Northern Current trajectory, completing its surface cyclonic circulation into the Catalan-Balearic Basin, near Mallorca Island (Fig. 3) (Salat et al. 2000).

Throughout his career, Jordi's main research interest has been linked with the formation and dynamics of the

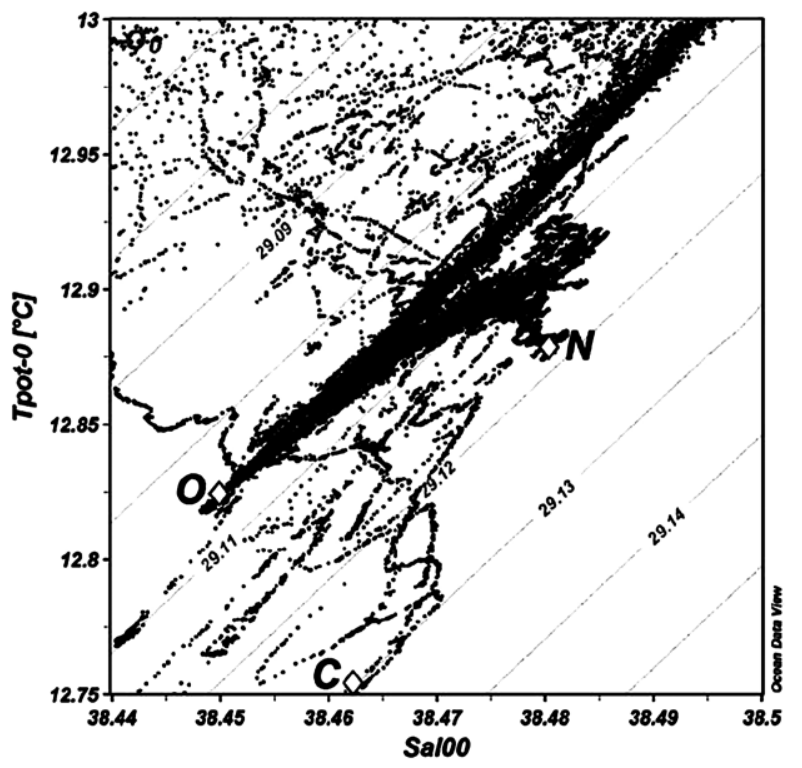

Fig. 4. - General $\theta$-S diagram for Western Mediterranean Deep Water found during the Eflubio-2005 cruise (March 2005), showing the water types $\mathrm{O}, \mathrm{N}$ and $\mathrm{C}$ involved in the formation of this water mass. Reproduced from Salat et al. (2009).

water masses in the western Mediterranean Sea. In 2005, we were together on the R/V Cornide de Saavedra, studying the thermohaline structure of the Balearic Front in the framework of the Eflubio project. We were north of Mallorca Island; in the morning, as I came to replace Jordi from the CTDs watch, I found him very excited. "Do you know", he said, "that during tonight's CTD cast, we found warm and salty water beneath the Le- 


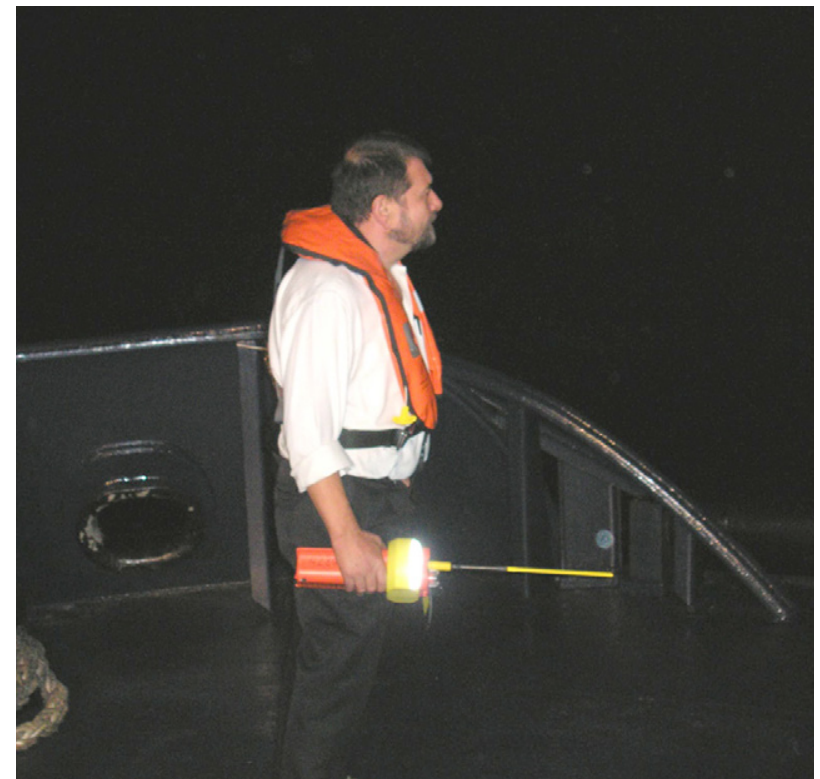

Fig. 5. - At sea during an experiment carried out in the framework of the project Establecimiento de un Sistema Español de Oceanografía Operacional (ESEOO). Source: Emilio Garcia Ladona.

vantine water mass? I took samples of this water. Please pay attention to the deep thermohaline anomalies at the following stations!" This was probably the first report on the widespread and massive formation of abnormally warm and salty deep water in the western Mediterranean region, which has received substantial attention thereafter (Fig. 4) (Salat et al. 2009, Puig et al. 2013).

During these last years, Jordi has paid special attention to the study of the Mediterranean response to climate change. He has maintained a long collaboration with the Catalan hydrometeorologist Josep Pascual, who has collected a unique series of measurements of sea temperature off Estartit (NW Catalan Sea), covering a 40-year observation period (Salat and Pascual 2002). He has also been involved in instrumentation and real-time sampling from different types of recreational vessels, including vessels participating in the Barcelona World Race, and in the development and testing of oceanographic sensors (Fig. 5).

\section{REFERENCES}

Arin L., Estrada M., Salat J., et al. 2005. Spatio-temporal variability of size fractionated phytoplankton on the shelf adjacent to the Ebro river (NW Mediterranean). Cont. Shelf Res. 25: 1081-1095.

http://dx.doi.org/10.1016/j.csr.2004.12.011
Ballester A., Cruzado A., Julia A., et al. 1972. Análisis automático y continuo de las características físicas, químicas y biológicas del mar. Publ. Técn. Patr. "J. de la Cierva": 72.

Cruzado A., Salat J. 1981. Interaction between the Canary current and the bottom topography. In: Richards F.A. (ed), Coastal Upwelling. Coast. and Estuar. Sci. 1: 67-175. http://dx.doi.org/10.1029/co001p0167

Estrada M., Varela R.A., Salat J., et al. 1999. Spatio-temporal variability of the winter phytoplankton distribution across the Catalan and North Balearic fronts (NW Mediterranean). J. Plankton Res. 21: 1-20. http://dx.doi.org/10.1093/plankt/21.1.1

Lleonart J., Salat J. 1992. VIT. Programa de análisis de pesqerias. Inf. Téc. Sci. Mar.: 168-169.

Lleonart J., Salat J., Macpherson E. 1985. CVPA, an expanded VPA with cannibalism. Application to a hake population. Fish. Res. 3: $61-79$ http://dx.doi.org/10.1016/0165-7836(85)90008-6

Lleonart J., Franquesa R., Salat J., et al. 1996. "Heures" a bio-economic model for Mediterranean fisheries, towards an approach for the evaluation of management strategies. Sci. Mar., 60: 427-430.

Lleonart J., Salat J., Torres G. 2000. Removing Allometric Effects of Body Size in Morphological Analysis, J. Theor. Biol. 205: 85-93 http://dx.doi.org/10.1006/jtbi.2000.2043

Lleonart J., Maynou F., Salat J. 2013. An analysis of fishing gear competition. Catalan fisheries as case studies. Sci. Mar. 77: 81-93. http://dx.doi.org/10.3989/scimar.03691.04A

Olivar M.P., Rubiés P., Salat J. 1992. Horizontal and vertical patterns of ichthyoplankton under intense upwelling regimes off Namibia. In: Payne A.I.L, Brink K.H., Mann K.H. et al., Benguela Trophic Functioning. (eds). S. Afr. J. Mar. Sci., 12: 71-82.

Palomera I., Olivar M.P., Salat J., et al. 2007. Small Pelagic Fish in the NW Mediterranean: An ecological review. Prog. Oceanogr. 74: 377-396. http://dx.doi.org/10.1016/j.pocean.2007.04.012

Puig P., Durrieu de Madron X., Salat J., et al. 2013. Thick bottom nepheloid layers in the western Mediterranean generated by deep dense shelf water cascading. Prog. Oceanogr. 111: 1-23. http://dx.doi.org/10.1016/j.pocean.2012.10.003

Sabatés A., Olivar M.P., Salat J., et al. 2007. Physical and biological processes controlling the distribution of fish larvae in the NW Mediterranean. Prog.Oceanogr. 74: 355-376. http://dx.doi.org/10.1016/j.pocean.2007.04.017

Salat J., Pascual J. 2002. The oceanographic and meteorological station at L'Estartit (NW Mediterranean) Tracking long-term hydrological change in the Mediterranean Sea. CIESM Workshop Ser. 16: 29-32.

Salat J., Manriquez M., Cruzado A. 1978. Hidrografía del Golfo de Sant Jordi. Campa-a DELTA (Abril 1970). Invest. Pesq. 42: 16-30.

Salat J., Sabatés A., Latasa M., et al. 2000. A Multidisciplinary Lagrangian Survey of the Spreading of Surface Low Salinity Waters along the Catalan Current in June 2000. Preliminary Results. Proc. 2000 LAPCOD meeting. http://www.rsmas.miami.edu/LAPCOD/2000-Ischia/abstracts/ absA102.html.

Salat J., Garcia M.A., Cruzado A., et al. 2002. Seasonal changes of water mass structure and shelf slope exchanges at the Ebro Shelf (NW Mediterranean). Cont. Shelf Res. 22: 327-348. http://dx.doi.org/10.1016/S0278-4343(01)00031-0

Salat J., Emelianov M., Puig P. 2009. From Bottom Water (Lacombe 1985) to New-WMDW since 2005. Possible shift on Open Sea Deep Convection. CIESM Workshop Ser. 38: 41-50. 